\title{
EFFECTIVE LASER-THERAPY OF POST-BURN SCARS
}

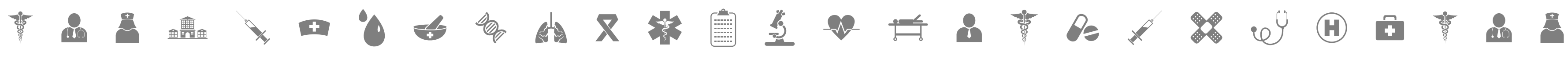 \\ INTRODUCTION \\ METHODS}

Post-burn scars, especially if hypertrophy occurs, have significant morbidity and psychological impact on patients. Scar contractures can restrict movement in joints and reduce self-care ability. Fractional ablative laser treatment (FA-LT) has a potential to reduce hypertrophy, improve scar texture and release incipient and mild contractures [1]. The most commonly used ablative lasers to treat scars are the $\mathrm{CO} 2$ and Erbium: YAG laser.

\section{CASE REPORT 1}

A 15 y.o. boy, flame burns, 35 \% TBSA gr. II-III, necrectomy + skin grafting. Hypertrophic hypertonic scars (Fig. 1.1). Repeated Erb:YAG-LT followed by FA-CO2-LT (Fig. 1.3). Significant (visible) improvement after one FACO2-LT session (Fig. 1.2).

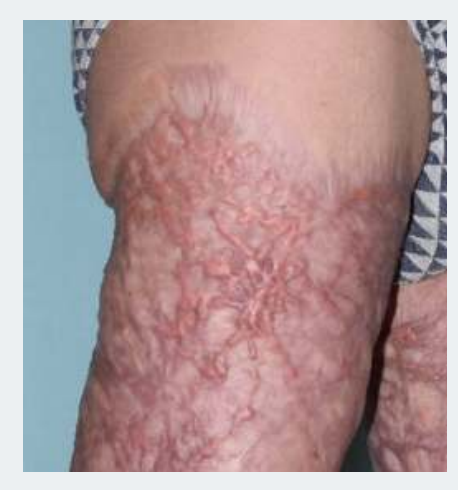

Fig. 1.1 Before FA-CO2-LT

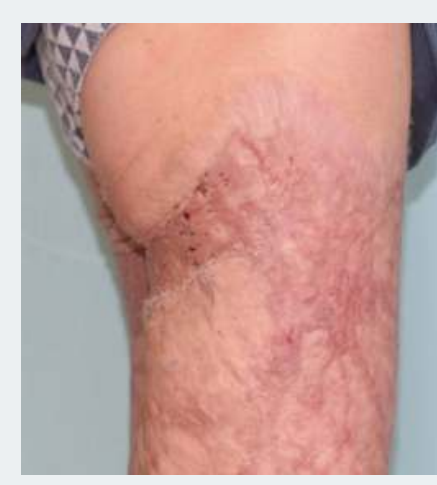

Fig. 1.2 2 months after
FA-CO2-LT

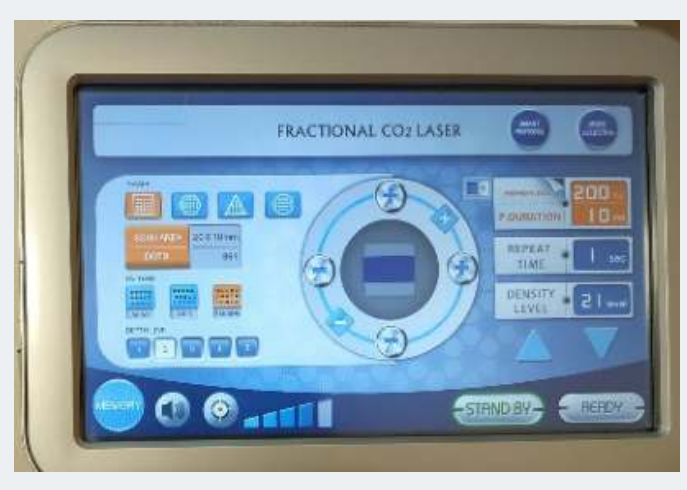

Fig. 1.3

\section{CASE REPORT 3}

A 7y.o. girl, hot water, $40 \%$ TBSA gr. II-III, necrectomy + skin grafting. Hypertrophic contracting scars (Fig.3.1). Repeated Erb:YAG-LT followed by FA-CO2-LT (Fig. 3.2). Significant improvement after two FA-CO2-LT sessions (Fig. 3.3).

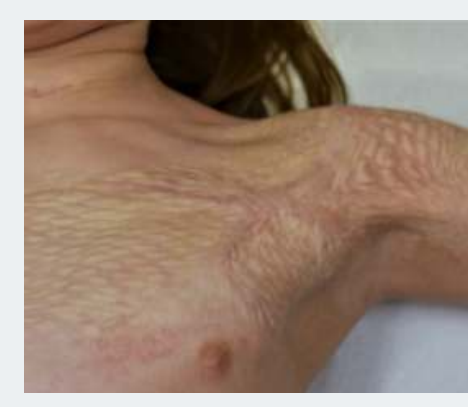

Fig. 3.1

Before FA-CO2-LT

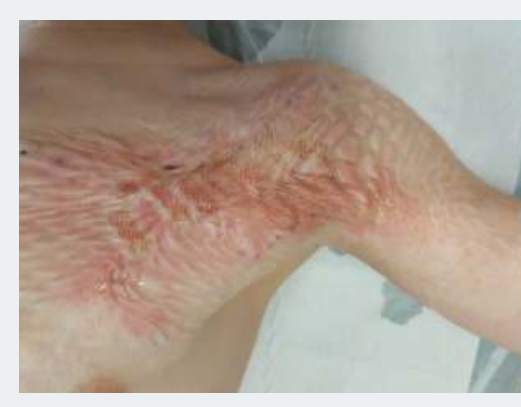

Fig. 3.2
Immediately after FA-CO2-LT

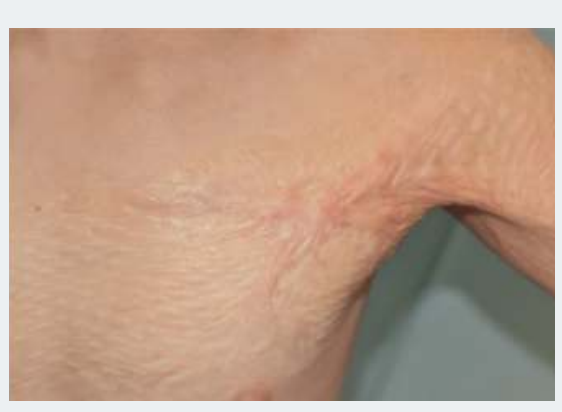

Fig. 3.3 3 months after $2^{\text {nd }} F A-C O 2-L T$

\section{RESULTS}

The changes after single session FA-CO2-LT: Visible reduction and improvement of scar hypertrophy and texture was evident in both, mature and immature scars (Graph 1). A significant reduction of tension was achieved in most of contracting scars without the need for further surgical release. The improvement of pigmentation were not evident. The decriptive statistics showed the total VSS decrease of both, mature and immature scars (Graph 2). The improvement of SCs texture was not evident after meshed skin grafting - the cross-linked uniform pattern was resistant to the first FA-CO2-LT. No complications in the subsequent course occured.

Graph

SCs hypertrophy [\% of SCs surface - median] Graph 2
Total VSS

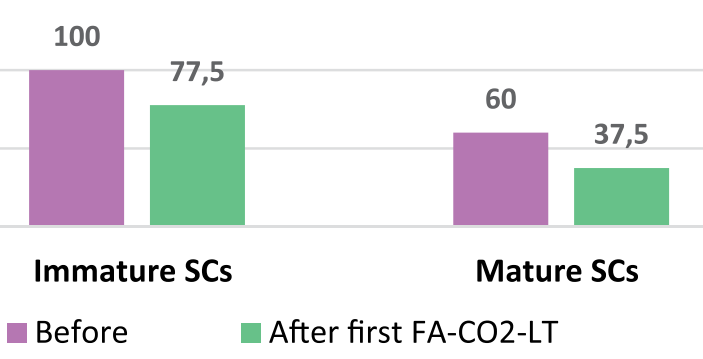

The total of 13 post-burn hypertrophic scars, 7 mature and 6 immature in 10 patients were treated by the fractional ablative CO2 LT (FA-CO2-LT) from December 1st, 2018, to July 30, 2019, during 2 treatment sessions in most of the patients. Evaluation of scars: before/after every LT, the Vancouver Scar Scale (VSS), Visual Analogue Scale (VAS) for tonus and texture, goniometry for joint range of motion and before/after photos for overall aesthetic outcome. Because of ongoing study, the authors focus on presentation of clinical improvement in some of these cases.

\section{CASE REPORT 2}

A 67 y.o. woman, flame burns, gr. Ilb on thumb, non-surgical treatment. Hypertrophic contracting scar restricted interphalangeal joint (IP) flexion (Fig. 2.1). FA-CO2-LT 4 and 7 months after healing (Fig. 2.2). Visible improvement - reduction of height, release of contracture with increase of IP joint flexion - from 45 to 65 degrees. Satisfactory functional and aesthetic result (Fig. 2.3)
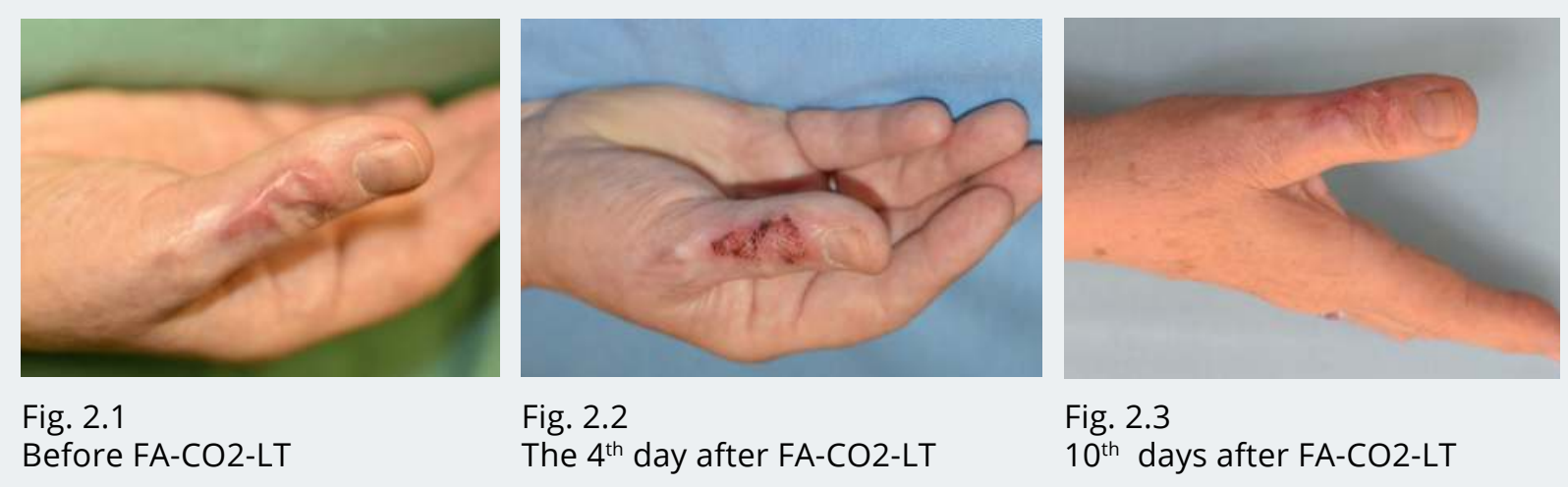

\section{CASE REPORT 4}

A 40 y.o. woman, flame burns, $25 \%$ TBSA gr. II-III, necrectomy and skin grafting of $5 \%$ TBSA. Subsequently hypertrophic non-contracting scars on the right arm (Fig. 4.1). FA-CO2-LT applied 3 years after the trauma (Fig. 4.2). Visible reduction of height, softening the texture and improvement of color after the first FA-CO2-LT (Fig. 4.3)

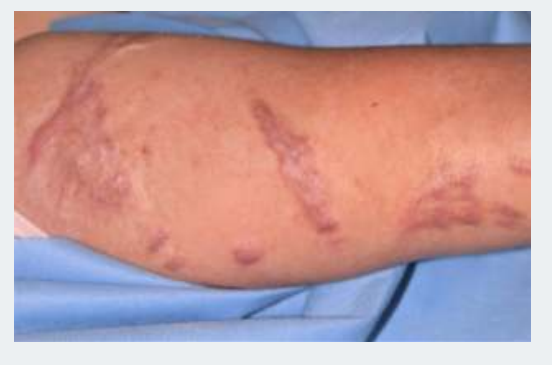

Fig. 4.1 Before FA-CO2-LT

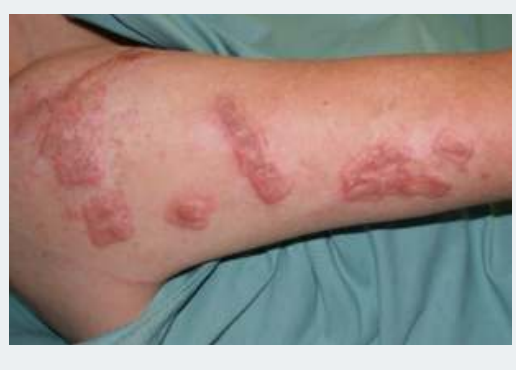
Fig. 4.2
Immediately after FA-CO2-LT

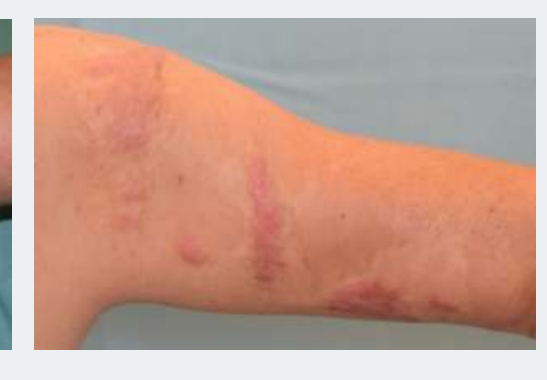

Fig. 4.3 $9^{\text {th }}$ day after FA-CO2-LT

\section{CONSLUSION}

The FA-CO2-LT is a safe and effective tool to reduce scar hypertrophy, improve scars texture and to release contracting scars and incipient contractures. The effect of FA-CO2-LT is visible after the first intervention in most of patients. Further treatment sessions achieve optimal functional and aesthetic results.

\section{REFERENCES}

[1] ISSLER-FISHER, Andrea C., et al. Ablative fractional CO2 laser for burn scar reconstruction: an extensive subjective and objective short-term outcome analysis of a prospective treatment cohort. Burns, 2017, 43.3: $573-582$. 